\title{
LONG-DISTANCE BROADCASTING
}

$\mathrm{D}^{\mathrm{r}}$ URING the earliest years of the development of radio broadcasting in Great Britain, efforts were made to restrict the area over which reception was necessary, in order to build up a service giving speech and music reproduction of the highest quality. It was with this object in mind that the regional scheme of broadcasting stations was developed. The country was divided up into sections or regions, each of which was served by two transmitters, one providing the national programme and the other a local or regional programme. In this way the majority of listeners were provided with two programmes emanating from a broadcasting station within about one hundred miles, which was considered to be the limiting range at which a reliable service could be obtained free from interference or fading.

The possibilities of long-distance broadcasting on a considerable scale were not generally admitted until about 1932 ; but since then, many millions of pounds have been spent by the several countries which have decided to establish wireless stations for this purpose. A review of the general development of such long. distance broadcasting was given by Sir Noel Ashbridge, Controller of Engineering of the British Broadcasting Corporation, in a Friday evening discourse at the Royal Institution on January 26.

After summarizing very briefly the main facts accompanying the development of radio communication over hundreds and thousands of miles, Sir Noel pointed out that the short wave-lengths in the region of fifty metres offer the best possibilities of covering long distances, by reason of the comparative ease with which such radio waves travel through the ionosphere. There are, however, many disadvantages and complications with short-wave transmission, which are not encountered in the use of medium waves over moderate distances. For example, in order to attain anything in the nature of a reliable service, it is practically necessary to choose a special wave-length for each transmission, depending upon the geographical location of the sending and receiving stations, the time of day and season of year and the degree of sunspot activity on the surface of the sun.

Two advantages of the use of short wave-lengths are, first, that much less power is required to cover a given distance on account of the comparative ease of transmission through the ionosphere; and secondly, it is practicable to design antenna arrays and reflectors so as to concentrate the radiated energy into a sector or zone in the desired direction. The difference in local time must be taken into account when considering the areas where reception is required, so that it is not normally necessary to transmit in all directions simultaneously.

It will thus be realized that the only really practicable means of giving a broadcasting service to any distant continent is by means of short-wave transmitters using directional aerials, so designed as to cover by zones the countries to be served. These zones can then be supplied with programmes simultaneously, by using several transmitters together, or successively for shorter periods, using one or more transmitters which can be changed over from one directional aerial system to another at suitable times. Provision must also be made for changes of wave-length to conform to the varying conditions of light and darkness, season and state of solar activity. It will be realized that in order to arrange for reception during the evening in all parts of the Empire, it is necessary to transmit almost continuously throughout the twenty-four hours.

After experimenting with a single transmitter as far back as 1927, the Daventry short-wave station was opened for service in December 1932, with two transmitters of $10-15$ kilowatts in power, and five antenna systems directed towards Australia, India, South Africa, West Africa and Canada respectively. The width of beam varied with the direction of transmission, and provision was made for the necessary changes of wave-length in each case.

In order to develop the service to the greatest extent possible, systematic experimental work was conducted by the B.B.C. with the view of improving the aerial systems, and in addition the co-operation of manufacturers was obtained to develop transmitters of considerably higher power than any hitherto available for short-wave radio communication. The first improvement included the substitution of horizontal aerials for the vertical dipoles previously used, and also the arrangement of the whole antenna system with its reflector to project the radiation at a small angle above the horizontal so as to give the efficient reflection from the ionosphere in the desired direction.

At the Daventry station, as it existed before the War, about thirty separate antenna arrays were provided, supported from twelve masts $500 \mathrm{ft}$. to $150 \mathrm{ft}$. in height, the whole covering a site area of about 160 acres. Additional transmitters with outputs varying from 50 to 100 kilowatts were also installed, and facilities are available for further additions. During this expansion and development, the introduction of foreign language broadcasting changed the character of the service somewhat, in so far as it became necessary to cater for world coverage instead of British Empire coverage only.

As a result of improvements on the above lines, a broadeasting service has been established on a perm. anent basis, giving large numbers of people great benefit by direct listening on short-wave broadcasting receivers. In addition, however, the efficiency of the service has been increased in many colonies by the establishment of Jocal relaying facilities, in which the signals from England are received on a high quality and somewhat elaborate central receiver, and relayed either by a separate medium wave broadcasting transmitter, or by line to subscribers connected to a central exchange.

From the engineering point of view, the main development described in Sir Noel's discourse has taken place in the astonishingly short period of five years. It has been based on many years research by some of the world's most eminent scientific workers, followed by much patient work by engineers ; and it is a matter of regret that temporarily many of the short-wave broadcasting services of the world have been directed to matters of international politics rather than to entertainment and the more peaceful type of informative programme for which they were intended.
R. L. S-R. 